\title{
Reactive Oxygen Species-Responsive Liposomes via Boronate-Caged Phosphatidylethanolamine
}

\author{
Jinchao Lou and Michael D. Best \\ Department of Chemistry \\ University of Tennessee \\ 1420 Circle Drive, Knoxville, TN, 37996 (USA) \\ E-mail:mdbest@utk.edu
}

Index

Supplemental Experimental Procedures .................. S2

Supplemental Figures................................... S3-S12

Characterization of Synthetic Compounds...................S13-S23 


\section{Evaluation of potential NR bleaching by $\mathrm{H}_{2} \mathrm{O}_{2}$}

Nile red $(0.1 \mathrm{mM})$ solutions were prepared in both methanol and $50 \%$ methanol in water $(\mathrm{v} / \mathrm{v})$, and then $100 \mu \mathrm{L}$ was transferred into a sub-micro cuvette. After taking an initial reading, $1 \mu \mathrm{L}$ $30 \% \mathrm{H}_{2} \mathrm{O}_{2}$ was added into the cuvette (final concentration $=98 \mathrm{mM}$ ). The fluorescence intensities were measured over time (Ex. Wavelength $=530 \mathrm{~nm}$, Ex/Em slit $=5 / 5 \mathrm{~nm}$, Em. Wavelength $=635(\mathrm{MeOH})$ or $\left.655\left(\mathrm{MeOH} / \mathrm{H}_{2} \mathrm{O}\right)\right)$. Cuvettes were sealed during measurement to prevent solvent evaporation.

\section{Restoration of NR fluorescence after liposome release using Triton X-100}

For liposome studies, 2 mM PC-based liposomes containing 75\% 1 were used. Kinetic curves were taken on a Cary Eclipse fluorometer using kinetic mode. Liposomes (100 $\mu \mathrm{L})$ were first added into a sub-micro cuvette. The excitation wavelength was set to be $552 \mathrm{~nm}$ and intensities at $635 \mathrm{~nm}$ were recorded over time. $1 \mu \mathrm{L} 30 \% \mathrm{H}_{2} \mathrm{O}_{2}$ was added at $1 \mathrm{~min}$, and $1 \mu \mathrm{L}$ $10 \%$ Triton $\mathrm{X}-100$ was added at $10 \mathrm{~min}$.

\section{TLC analysis of free lipid 1 after treatment of hydrogen peroxide}

$1 \mu \mathrm{L}$ of $30 \% \mathrm{H}_{2} \mathrm{O}_{2}$ was added to $0.5 \mathrm{~mL}$ of a $1 \mathrm{mg} / \mathrm{mL}$ stock solution of lipid 1 in $50 \%$ methanol/chloroform and incubated at room temperature for 2 hours. The reaction mixture, alongside separate standards for lipid $\mathbf{1}$ as well as DOPE were spotted onto a normal aluminum-backed silica gel TLC plate. The plates were developed with $10 \%$ or $20 \% \mathrm{MeOH}$ $\mathrm{CHCl}_{3}$ as eluant and were visualized with $\mathrm{KMnO}_{4}$ stain after developing.

\section{Mass spectrometry analysis of free lipid 1 after hydrogen peroxide treatment}

For free lipid 1, $1 \mu \mathrm{L}$ of $30 \% \mathrm{H}_{2} \mathrm{O}_{2}$ was added into $30 \mu \mathrm{L}$ of a $25 \mathrm{mM}$ stock solution lipid 1 in $50 \%$ methanol/chloroform. The mixture was next diluted into $5 \mathrm{~mL}$ with methanol before being subjected to the mass spectrometer. The final concentration was $\sim 150 \mu \mathrm{M}$. ESI positive mode was used for detection.

\section{NMR analysis of free lipid 1 or liposomes containing 1 after treatment of $\mathrm{H}_{2} \mathrm{O}_{2}$}

For analysis of free lipid, compound 1 was dissolved in a mixture of $\mathrm{CDCl}_{3} / \mathrm{CD}_{3} \mathrm{OD} / \mathrm{D}_{2} \mathrm{O}=65 / 25 / 4(\mathrm{v} / \mathrm{v})$ at a concentration of $2 \mathrm{mg} / \mathrm{mL}$. A $0.5 \mathrm{~mL}$ solution was transferred into an NMR tube for analysis. After taking an initial reading, $1 \mu \mathrm{L}$ of $30 \% \mathrm{H}_{2} \mathrm{O}_{2}$ was added directly into the NMR tube and the mixture was mixed well by gentle shaking. NMR spectra were recorded over time and analyzed by MestReNova.

For NMR analysis of liposomes, $2 \mathrm{mM}$ liposomes composed of $100 \%$ lipid 1 without dye encapsulation were prepared. $5 \mu \mathrm{L}$ of $30 \% \mathrm{H}_{2} \mathrm{O}_{2}$ was added into $500 \mu \mathrm{L}$ liposome solution. After being incubated at room temperature for five minutes, excess peroxide was quenched by adding $50 \mu \mathrm{L} 1 \mathrm{M}$ thiosulfate followed by vigorous vortexing. Next, water was removed under reduced pressure and the vial was placed under vacuum for an extra one hour. NMR samples were prepared by dissolving the residue in $0.6 \mathrm{~mL} 20 \% \mathrm{CDCl}_{3} / \mathrm{CD}_{3} \mathrm{OD}(\mathrm{v} / \mathrm{v})$. 
A

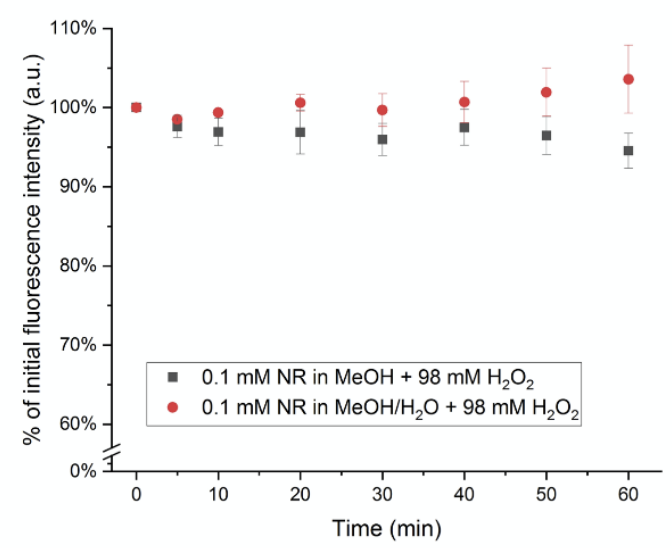

B

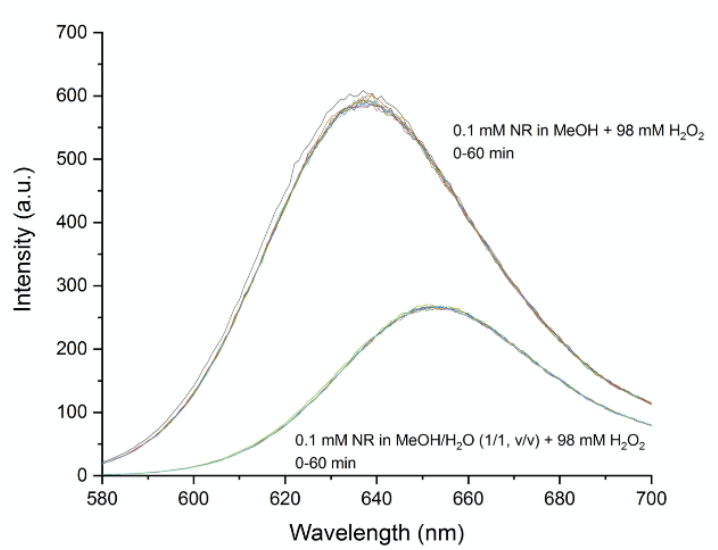

Figure S1. A. NR fluorescence intensity change over time when treating NR with excess $\mathrm{H}_{2} \mathrm{O}_{2}$ in $\mathrm{MeOH}$ or $\mathrm{MeOH} / \mathrm{H}_{2} \mathrm{O}$. No significant intensity decrease could be observed within 60 min. Error bars indicate standard errors from three experiments. B. Sample raw fluorescence emission spectra (Ex. Wavelength=530 nm, ex. Slit=5 nm, em. Slit=5 nm).
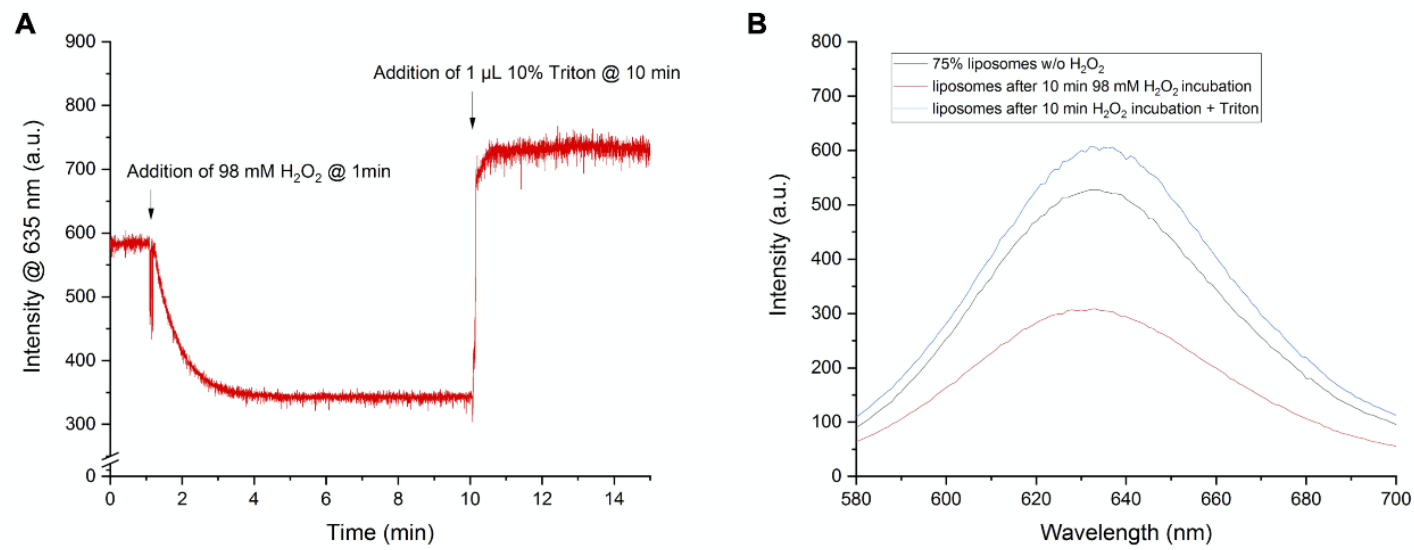

Figure S2. A. Kinetic curve of NR fluorescence in liposomes at $635 \mathrm{~nm}$ after adding $\mathrm{H}_{2} \mathrm{O}_{2}$ and then later Triton $\mathrm{X}-100$. PC liposomes containing $75 \% 1$ were first treated with $\mathrm{H}_{2} \mathrm{O}_{2}$ to trigger content release as is indicated by decrease in NR fluorescence. After plateauing, Triton X-100 was added to re-dissolve NR, which restored its fluorescence. B. Full fluorescence emission spectra before release, after $\mathrm{H}_{2} \mathrm{O}_{2}$ addition and after Triton $\mathrm{X}-100$ addition. (Ex. Wavelength $=552 \mathrm{~nm}$, ex. Slit=5 nm, em. Slit=5 nm) 


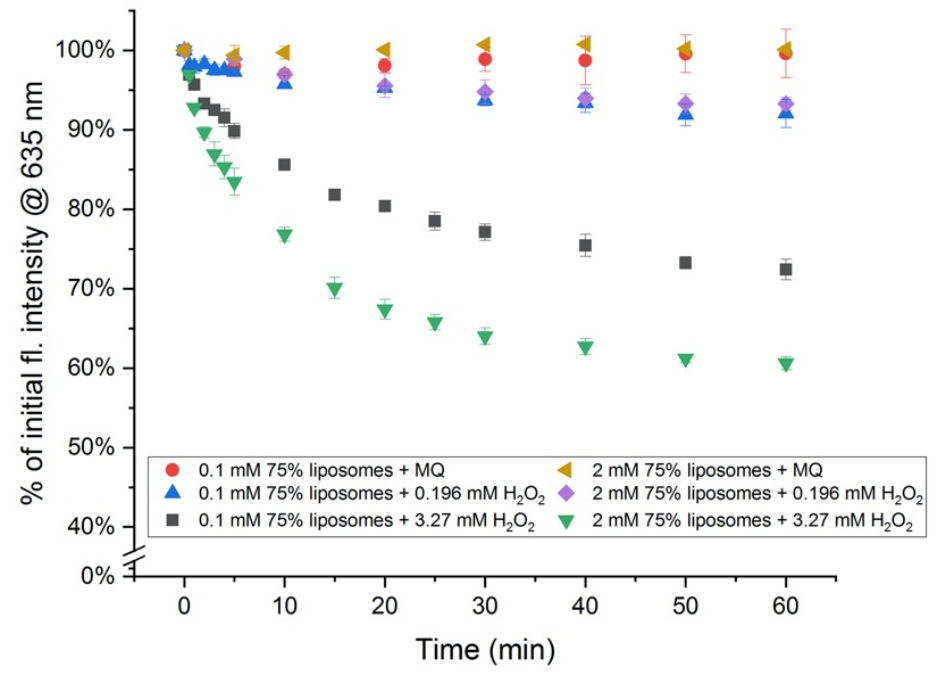

Figure S3. Nile red release profiles using different concentrations of PC-based liposomes containing $75 \%$ of $1.0 .1 \mathrm{mM}$ liposomes showed comparable results to $2 \mathrm{mM}$ liposomes when being treated with $0.196 \mathrm{mM} \mathrm{H}_{2} \mathrm{O}_{2}$, while slightly less release was observed when these were treated with $3.27 \mathrm{mM} \mathrm{H}_{2} \mathrm{O}_{2}$. Control experiments in which $2 \mathrm{mM}$ and $0.1 \mathrm{mM}$ liposomes were treated with $\mathrm{MQ}$ did not show background release. Error bars denotes standard errors from at least three independent experiments.

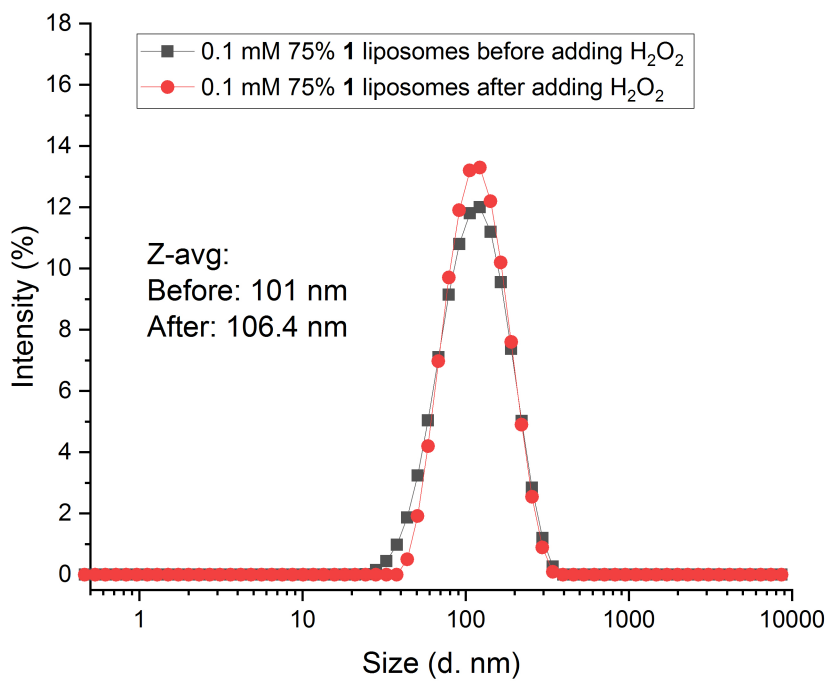

Figure S4. DLS size distribution plots for $0.1 \mathrm{mM}$ PC-based liposomes containing $75 \% 1$ before and after $\mathrm{H}_{2} \mathrm{O}_{2}$ addition. Stable liposomes were formed and no obvious changes in particle size could be observed after $\mathrm{H}_{2} \mathrm{O}_{2}$ treatment. 


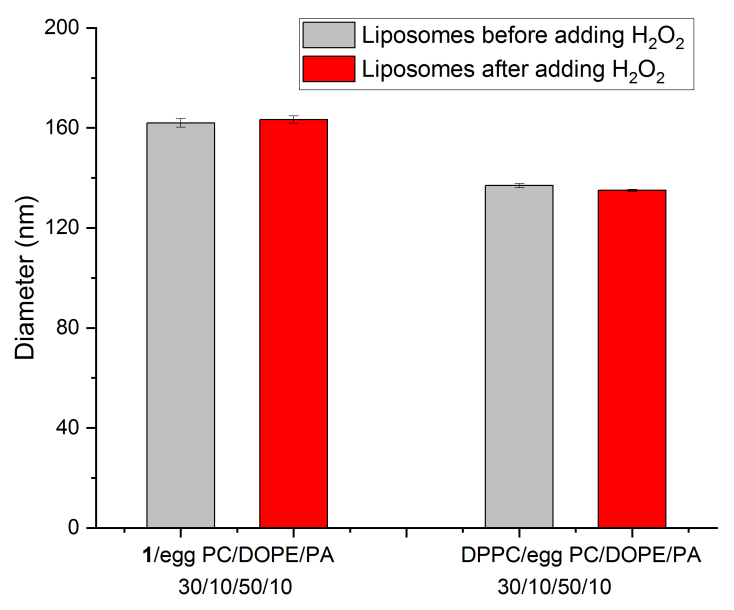

Figure S5. DLS results using liposomes containing 30\% lipid 1, 50\% DOPE, 10\% PC and 10\% PA before and after release via the ANTS/DPX assay. Uniformly sized stable liposomes were initially formed. Minimal changes in particle sizes were observed after adding $\mathrm{H}_{2} \mathrm{O}_{2}$. Error bars presented indicate standard errors from at least three studies.

A

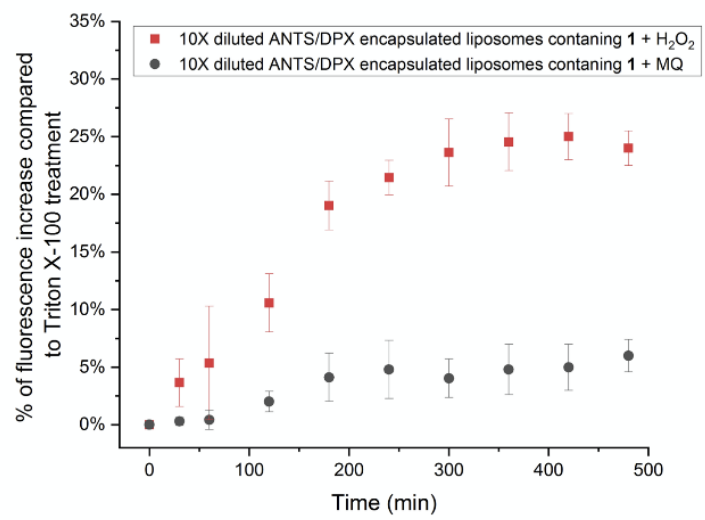

B

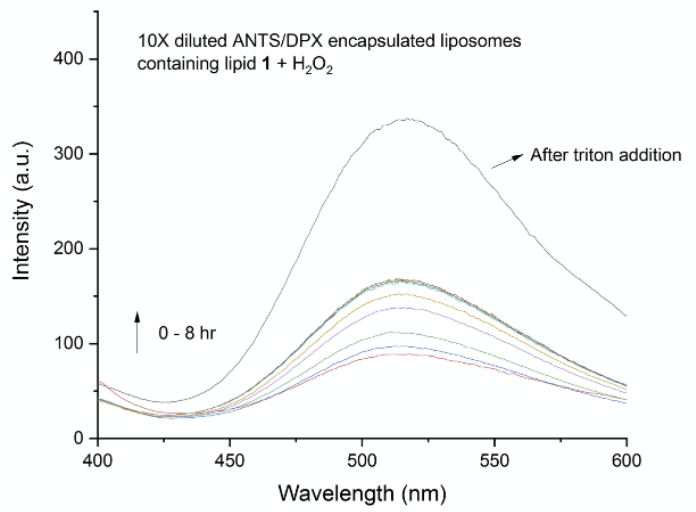

Figure S6. A. ANTS/DPX release profile for 10X diluted liposomes containing $30 \%$ lipid 1, 50\% DOPE, 10\% PC and 10\% PA. Comparable increases in fluorescence were observed, indicating concentration does not affect release extent. B. Sample raw fluorescence emission spectra. Fluorescence intensity was recorded over time (Ex. Wavelength $=350 \mathrm{~nm}$, ex. Slit=20 $\mathrm{nm}$, em. Slit=20 nm). 


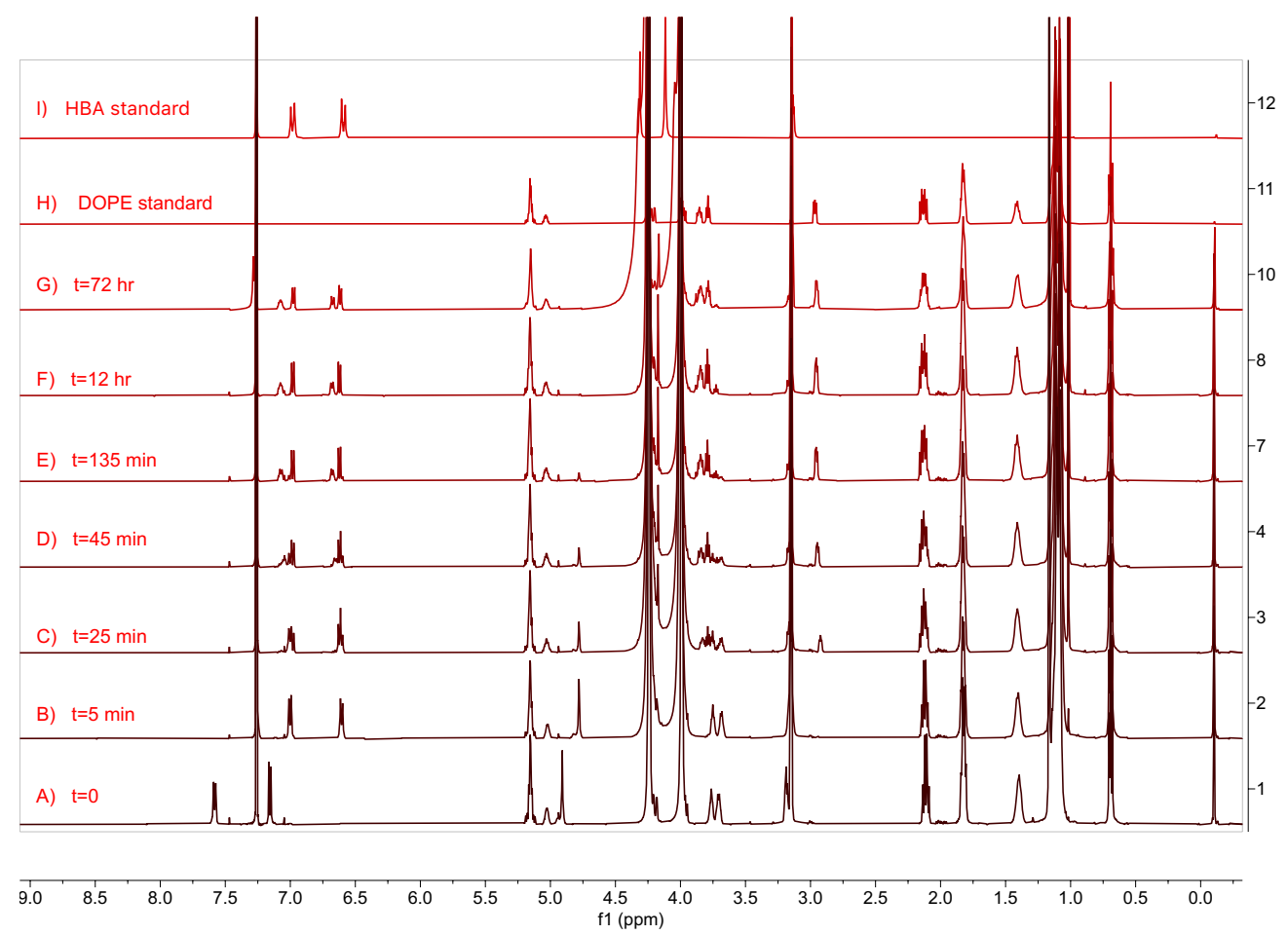

Figure S7. Time-dependent NMR analysis for lipid 1 in $\mathrm{CDCl}_{3} / \mathrm{CD}_{3} \mathrm{OD} / \mathrm{D}_{2} \mathrm{O}=65 / 25 / 4$ (v/v) upon treatment with hydrogen peroxide. Trace A: lipid 1 before adding $\mathrm{H}_{2} \mathrm{O}_{2}$. Trace $\mathrm{B}$ to $\mathrm{G}$ : spectra for lipid 1 upon $\mathrm{H}_{2} \mathrm{O}_{2}$ treatment, which were taken over time. Trace $\mathrm{H}$ : DOPE standard. Trace I: 4-hydroxybenzyl alcohol (HBA) standard.
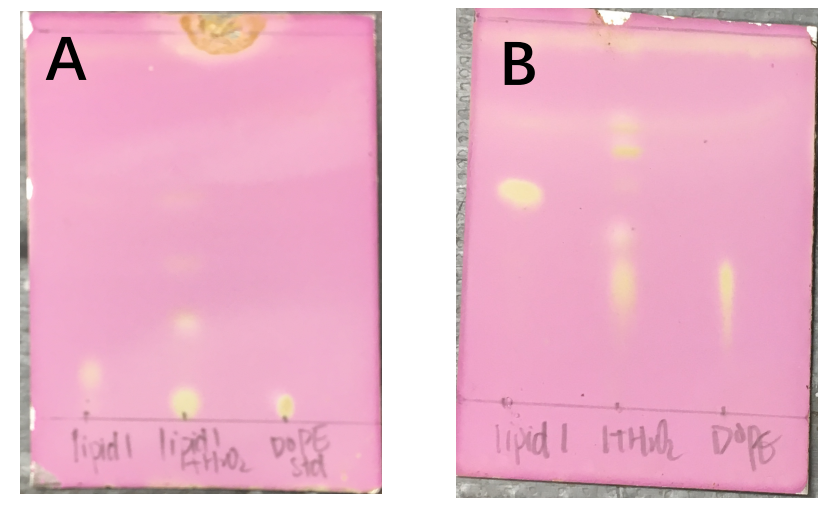

Figure S8. TLC analysis of free lipid 1 after adding $\mathrm{H}_{2} \mathrm{O}_{2}$. Plates were developed in $\mathbf{A}$. $10 \%$ $\mathrm{CH}_{3} \mathrm{OH} / \mathrm{CHCl}_{3}$, B. $20 \% \mathrm{CH}_{3} \mathrm{OH} / \mathrm{CHCl}_{3}$. Lane 1: lipid 1 standard; Lane 2: lipid $1+\mathrm{H}_{2} \mathrm{O}_{2}$; Lane 3: DOPE standard. After $\mathrm{H}_{2} \mathrm{O}_{2}$ incubation, a new spot appeared with the same $\mathrm{R}_{\mathrm{f}}$ value as DOPE. 


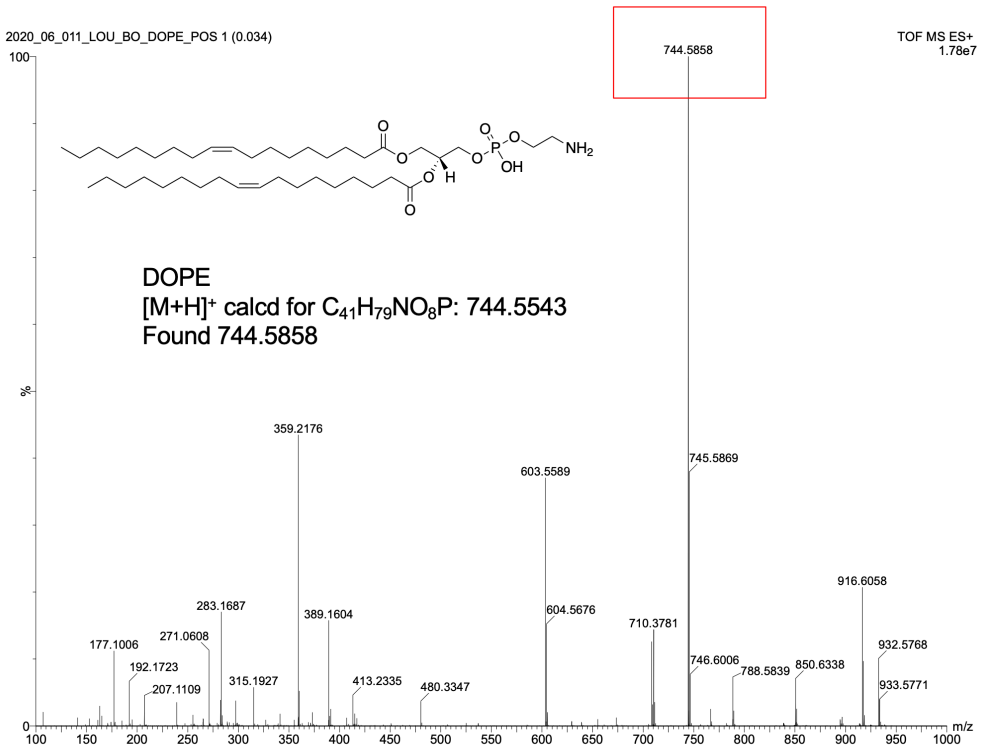

Figure S9. Mass spectrum including a peak matching DOPE after treating free lipid 1 with hydrogen peroxide.

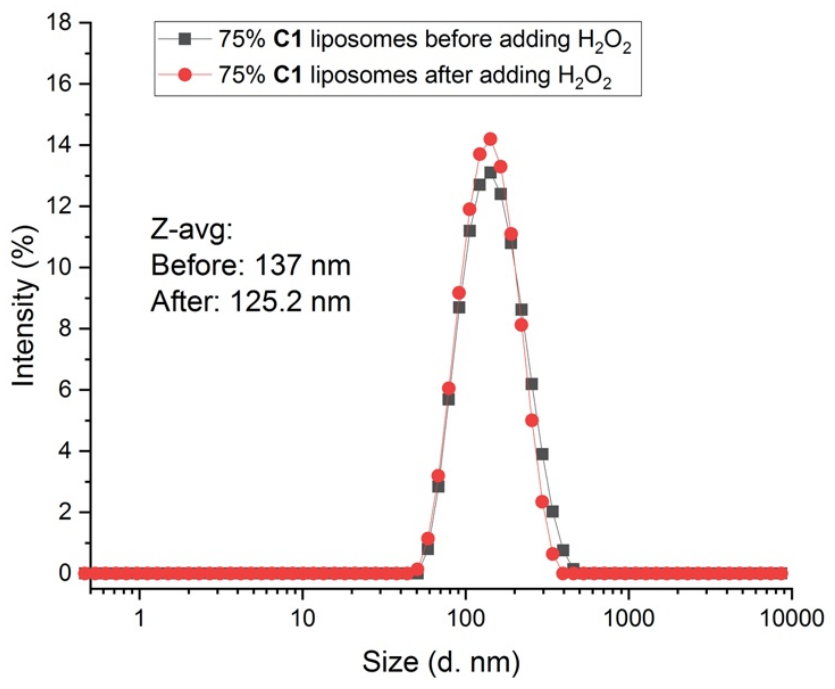

Figure S10. DLS size distribution plots for $75 \% \mathrm{C} 1$ liposomes before and after $\mathrm{H}_{2} \mathrm{O}_{2}$ addition. No significant change was observed in particle size after $\mathrm{H}_{2} \mathrm{O}_{2}$ treatment. 


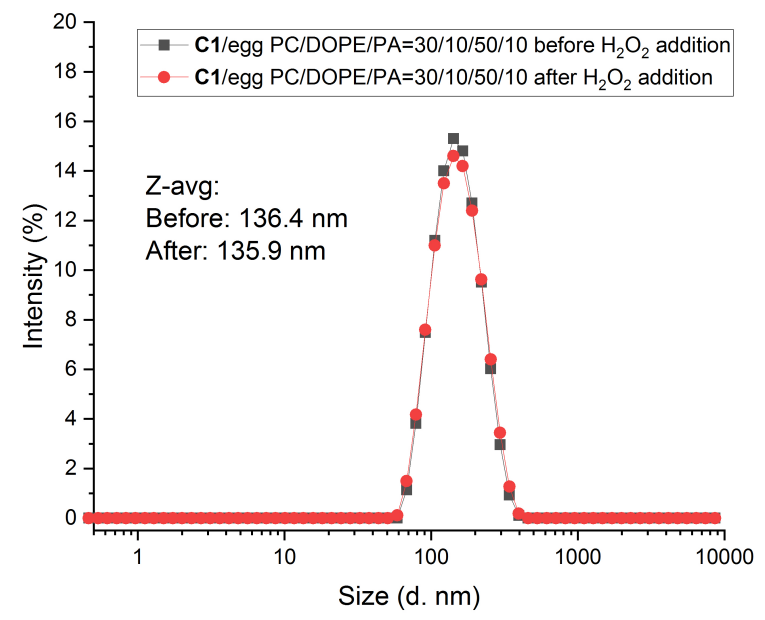

Figure S11. DLS size distribution plots for ANTS/DPX-encapsulated $\mathbf{C} 1$ liposomes containing $30 \%$ C1, $10 \%$ egg PC, 50\% DOPE and 10\% PA before and after $\mathrm{H}_{2} \mathrm{O}_{2}$ addition. Minimal changes were observed in particle sizes.

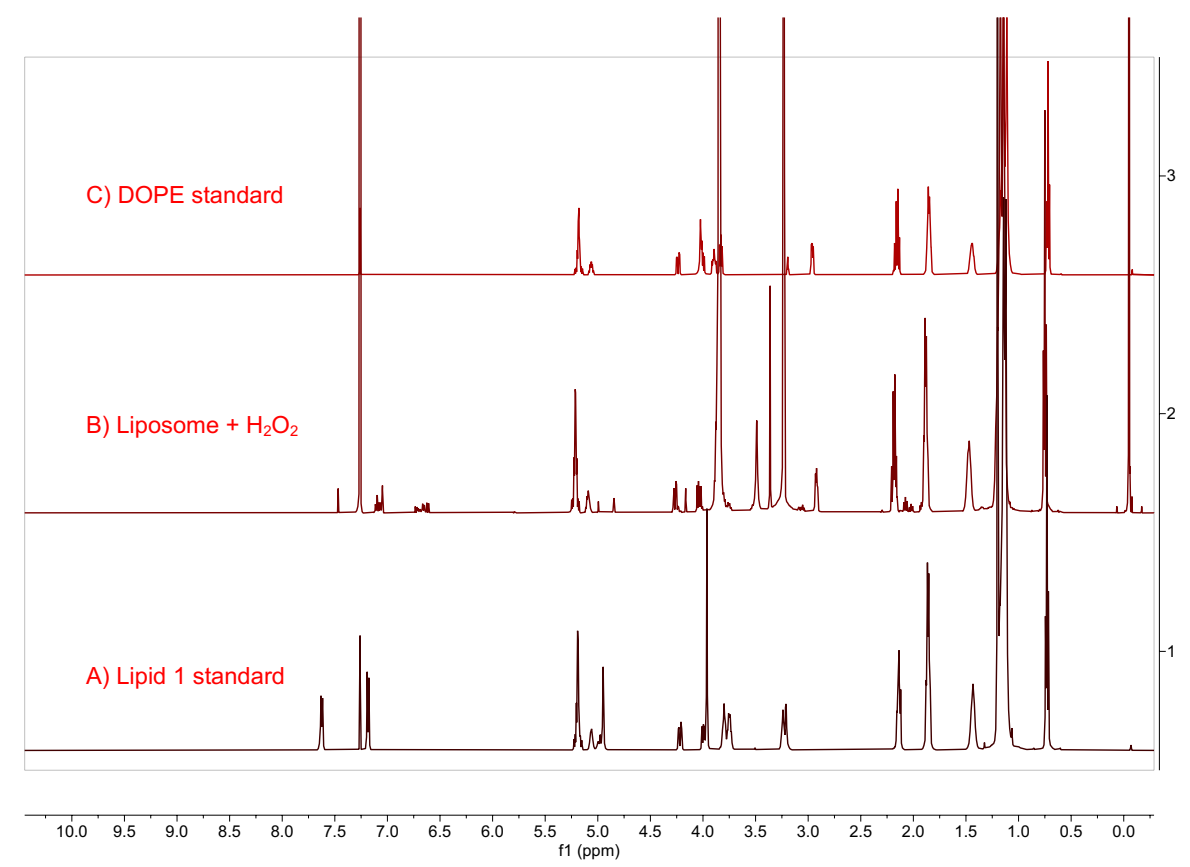

Figure S12. NMR analysis for liposomes composed of $100 \%$ lipid 1 after treatment with $\mathrm{H}_{2} \mathrm{O}_{2}$ for five minutes. Excess $\mathrm{H}_{2} \mathrm{O}_{2}$ was quenched and water was removed before re-dissolving the mixture in $20 \% \mathrm{CD}_{3} \mathrm{OD} / \mathrm{CDCl}_{3}$ for $\mathrm{NMR}$ analysis. All lipid 1 was oxidized within five minutes. Trace A: lipid 1 standard; Trace B: $100 \%$ liposome after 5 min $\mathrm{H}_{2} \mathrm{O}_{2}$ incubation; Trace C: DOPE standard. 

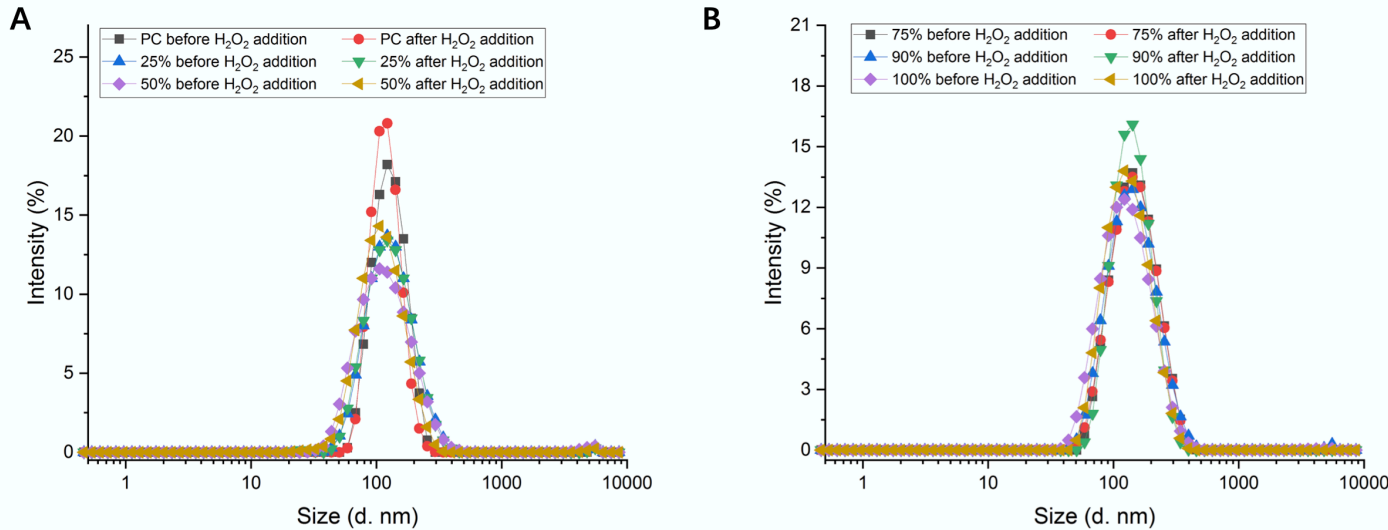

Figure S13. Raw DLS size distribution plots for liposomes containing 1 used in NR release assays. A. PC based liposomes containing $0,25 \%$ and $50 \%$ lipid 1 before and after adding $\mathrm{H}_{2} \mathrm{O}_{2}$. B. $\mathrm{PC}$ based liposomes containing $75 \%, 90 \%$ and $100 \%$ lipid 1 before and after adding $\mathrm{H}_{2} \mathrm{O}_{2}$. Samples are separated for the sake of clarity.
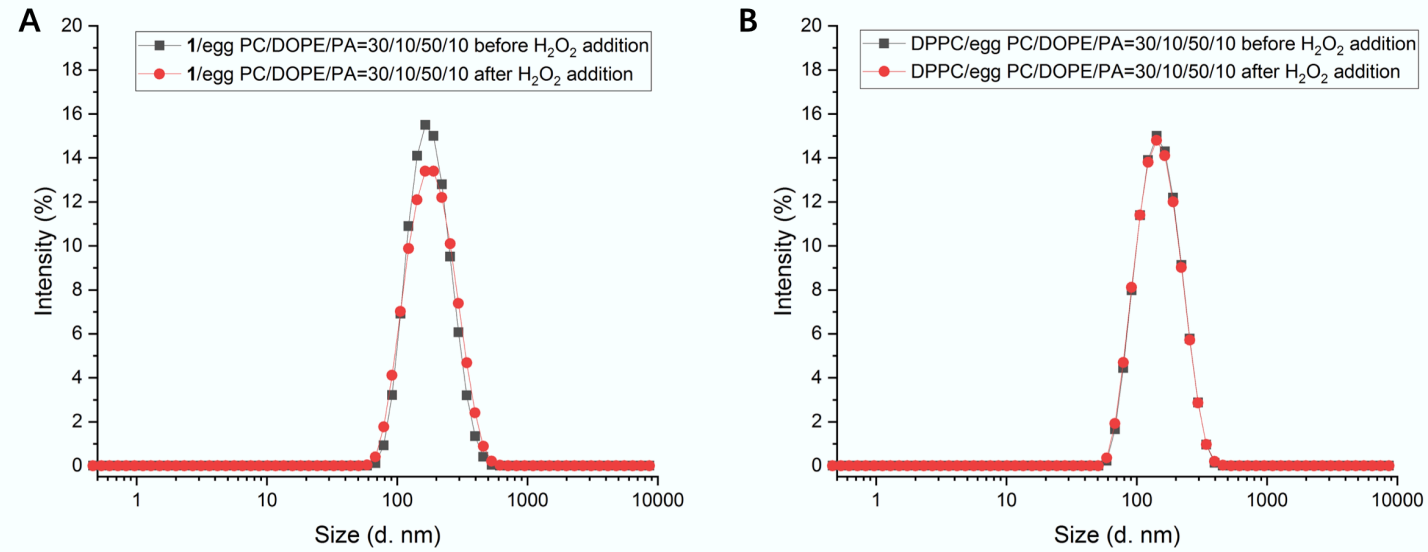

Figure S14. Raw DLS size distribution plots for liposomes used in ANTS/DPX release assays. A. Liposomes containing 30\% lipid 1, 10\% egg PC, 50\% DOPE and 10\% PA before and after adding $\mathrm{H}_{2} \mathrm{O}_{2}$. B. Control liposomes containing 30\% DPPC, $10 \%$ egg PC, 50\% DOPE and 10\% PA before and after adding $\mathrm{H}_{2} \mathrm{O}_{2}$. Samples are separated for the sake of clarity. 


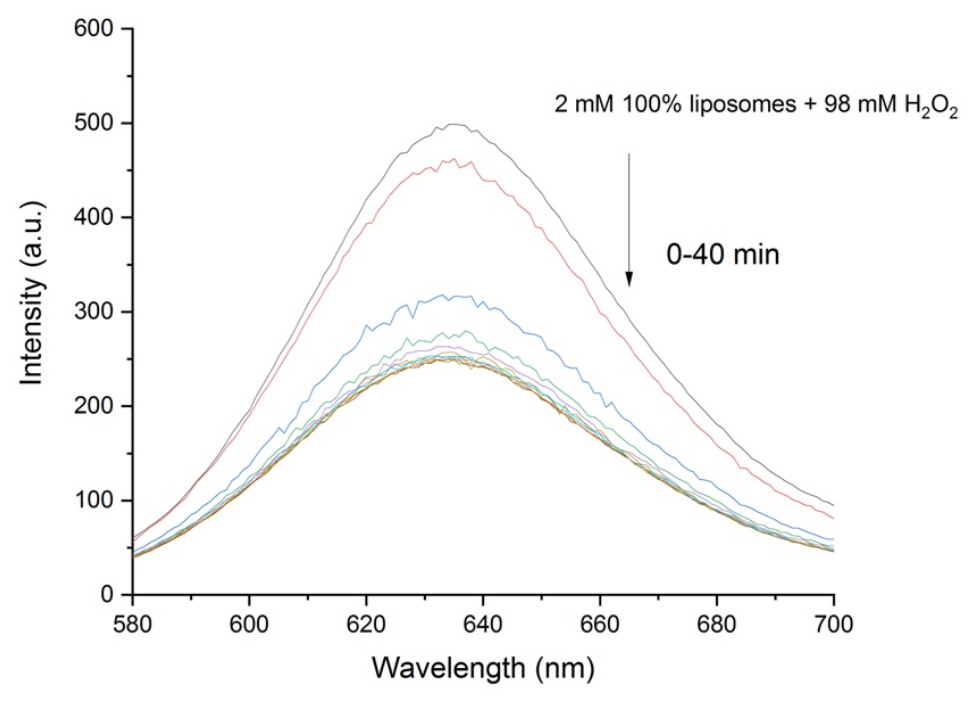

Figure S15. Sample raw fluorescence emission spectra for $2 \mathrm{mM}$ NR-containing liposomes composed of $100 \%$ lipid 1 after adding $98 \mathrm{mM} \mathrm{H}_{2} \mathrm{O}_{2}$. Fluorescence intensities were recorded over time. (Ex. Wavelength=552 nm, ex. Slit=5 nm, em. Slit=5 nm)

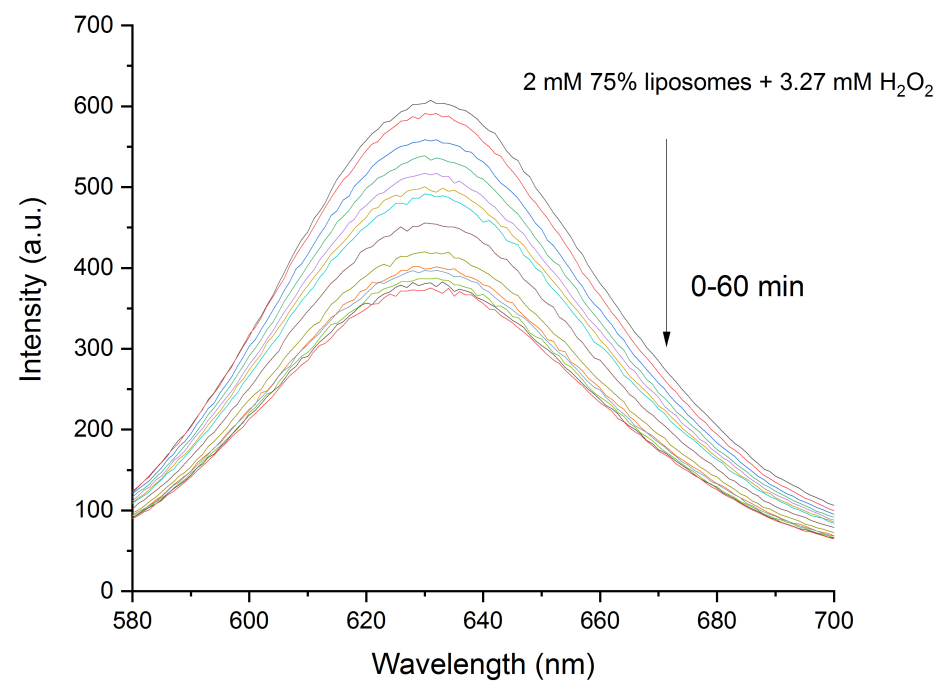

Figure S16. Sample raw fluorescence emission spectra for $2 \mathrm{mM}$ PC-based liposomes encapsulating Nile red containing $75 \%$ lipid 1 after adding $3.27 \mathrm{mM} \mathrm{H}_{2} \mathrm{O}_{2}$. Fluorescence intensities were recorded over time. (Ex. Wavelength $=552 \mathrm{~nm}$, ex. Slit=5 nm, em. Slit=5 nm) 


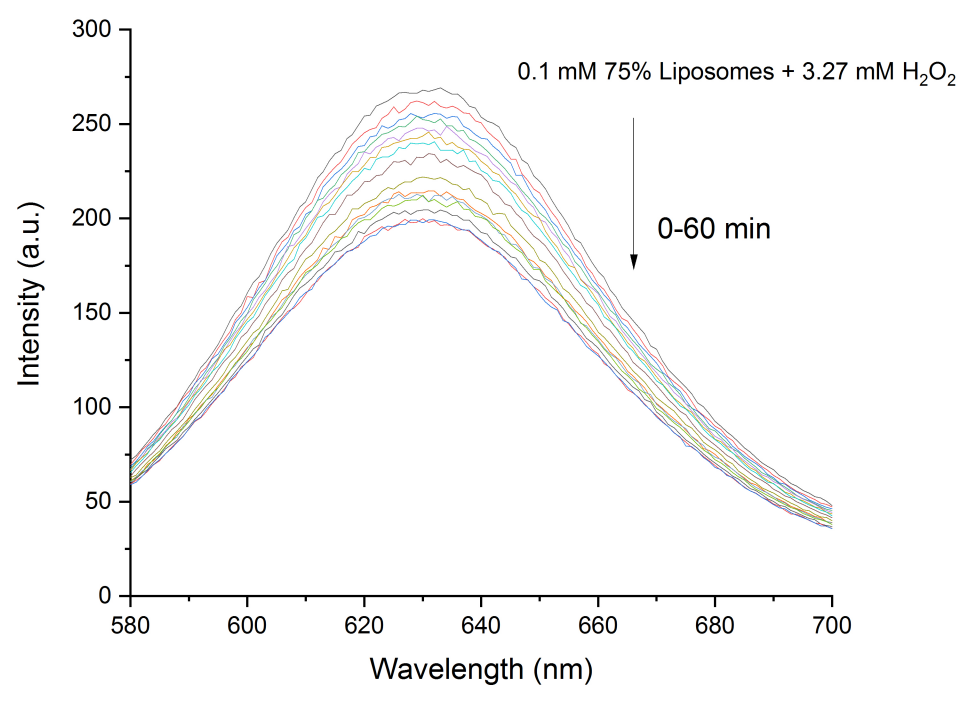

Figure S17. Sample raw fluorescence emission spectra for $0.1 \mathrm{mM}$ PC-based liposomes encapsulating Nile red containing $75 \%$ lipid 1 after adding $3.27 \mathrm{mM} \mathrm{H}_{2} \mathrm{O}_{2}$. Fluorescence intensities were recorded over time. (Ex. Wavelength $=552 \mathrm{~nm}$, ex. Slit=5 nm, em. Slit=10 nm)

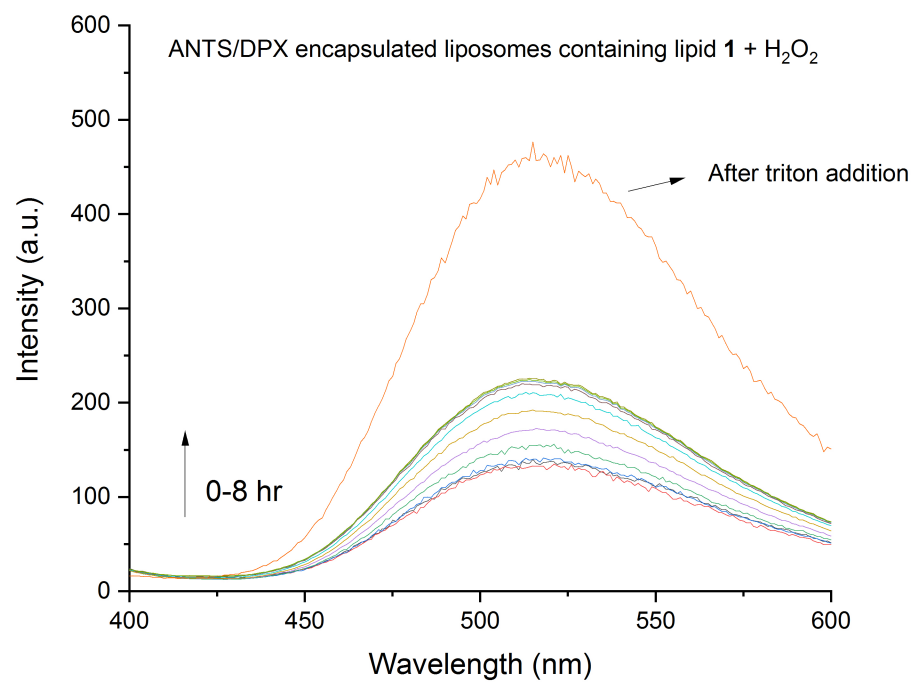

Figure S18. Sample raw fluorescence emission spectra for liposomes containing $30 \%$ lipid $\mathbf{1}$, $10 \%$ egg PC, 50\% DOPE and 10\% PA used in ANTS/DPX release assay after $\mathrm{H}_{2} \mathrm{O}_{2}$ addition. Fluorescence intensities were recorded over time. (Ex. Wavelength=350 nm, ex. Slit=10 nm, em. Slit=10 nm) 

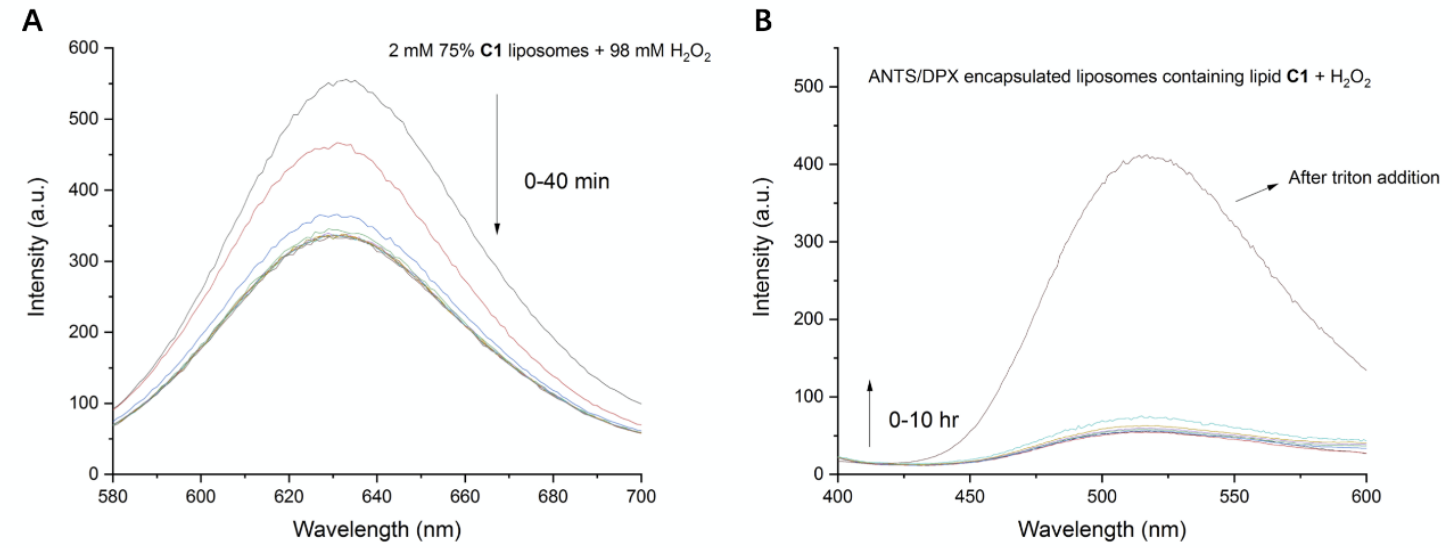

Figure S19. Sample raw fluorescence emission spectra for A. 2 mM 75\% C1 liposomes upon $\mathrm{H}_{2} \mathrm{O}_{2}$ treatment. Fluorescence intensities were recorded over time. (Ex. Wavelength=552 nm, ex. Slit=5 nm, em. Slit=5 nm) B. liposomes containing 30\% lipid C1, 10\% egg PC, 50\% DOPE and $10 \%$ PA used in ANTS/DPX release assay after $\mathrm{H}_{2} \mathrm{O}_{2}$ addition. Fluorescence intensity was recorded over time. (Ex. Wavelength=350 nm, ex. Slit=10 nm, em. Slit=10 nm) 


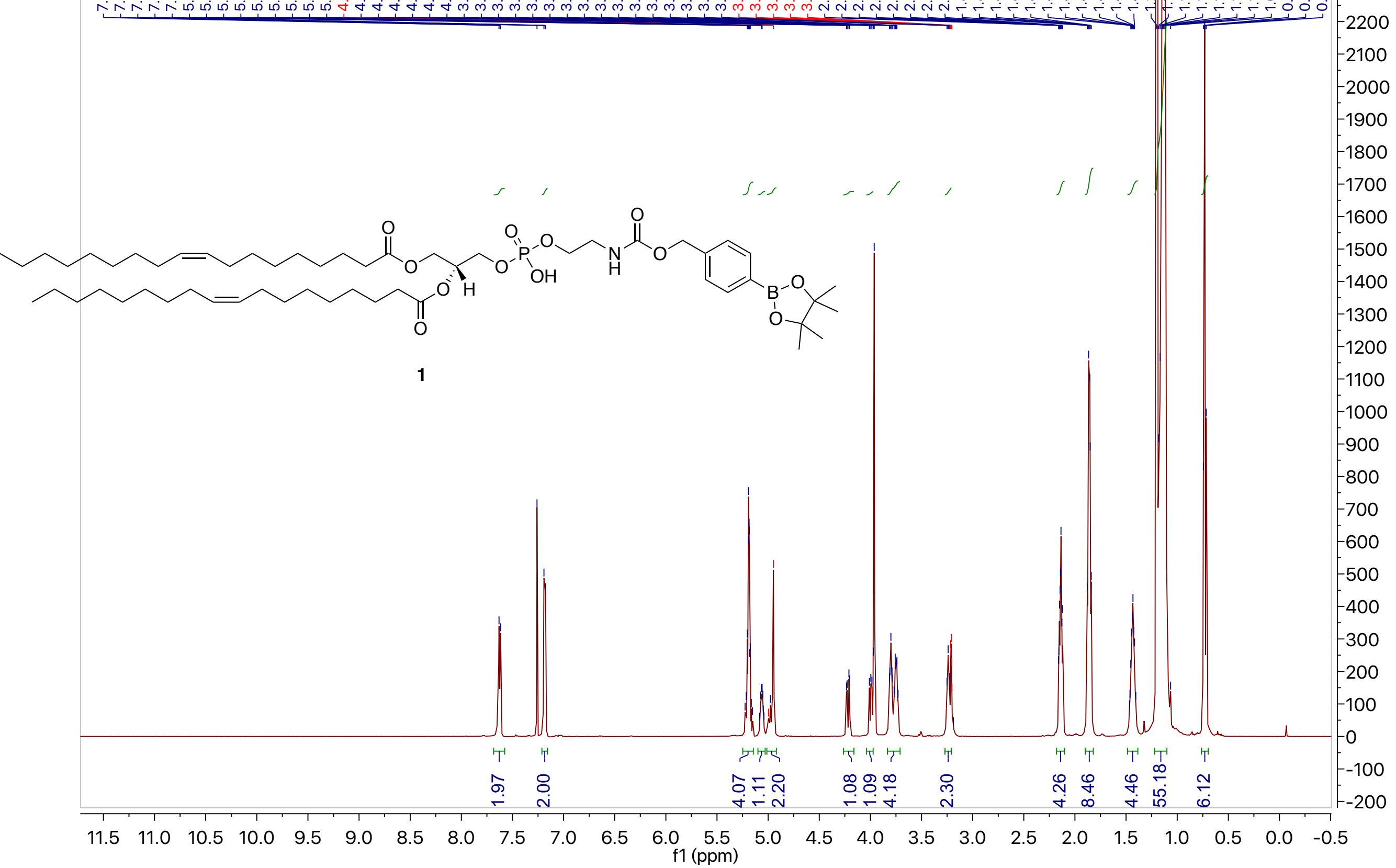




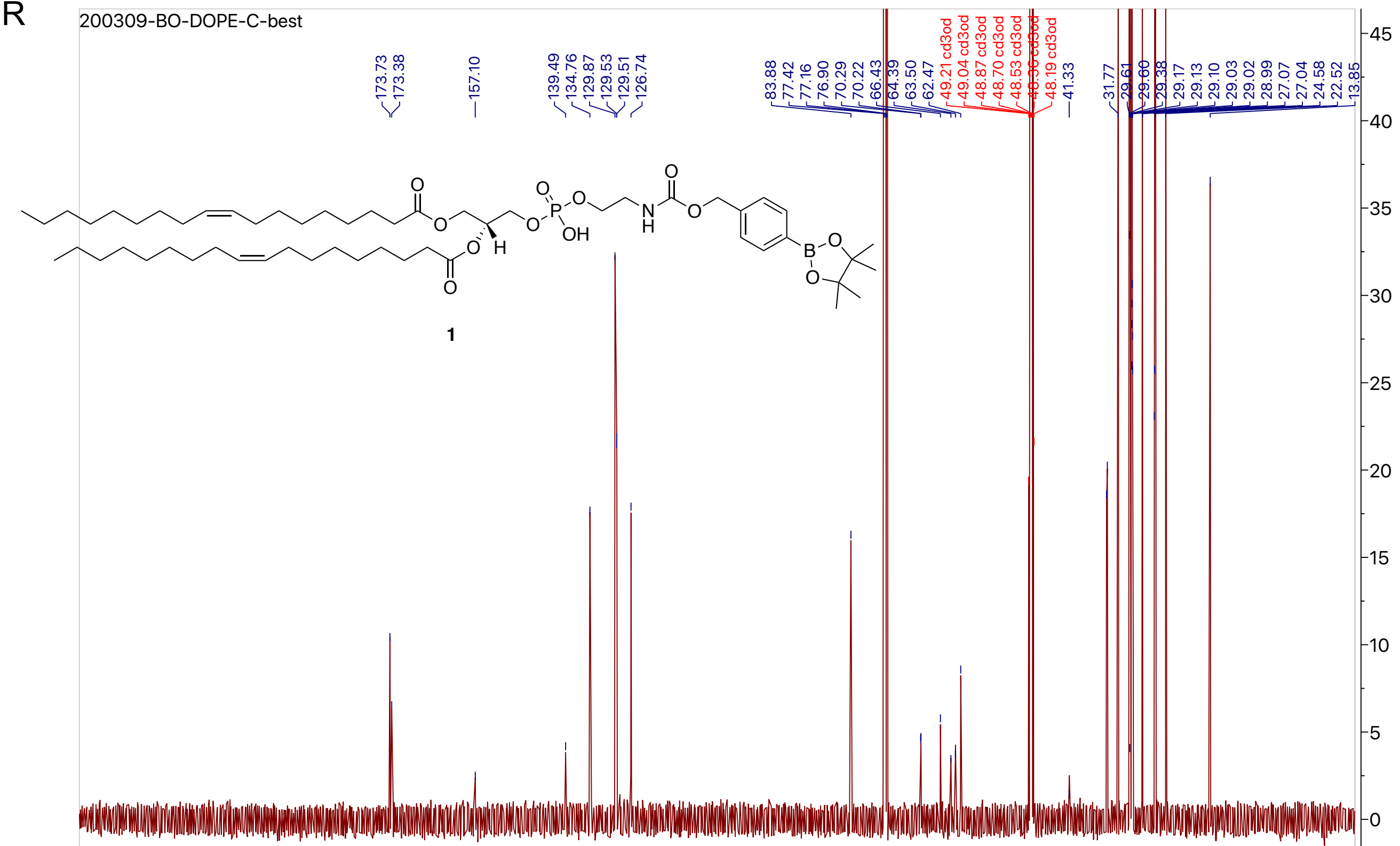




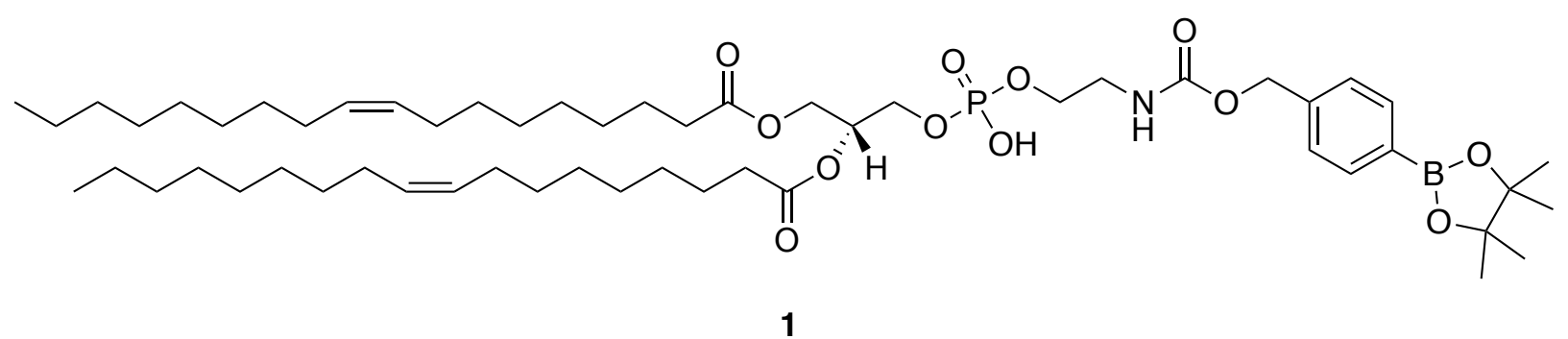



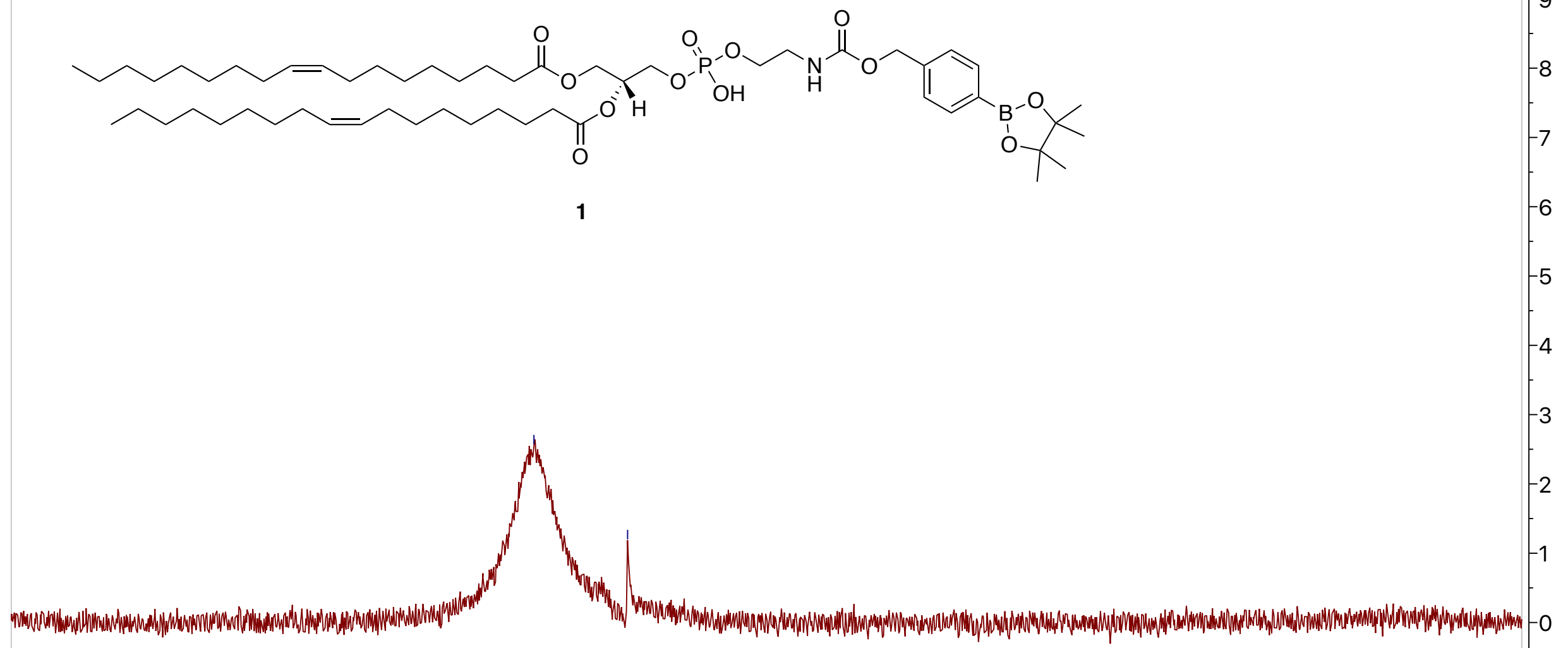

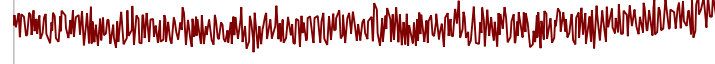

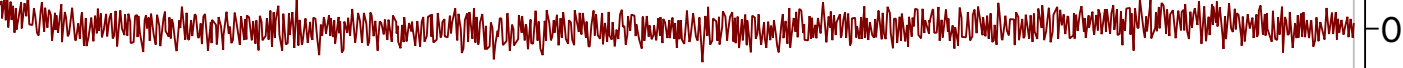

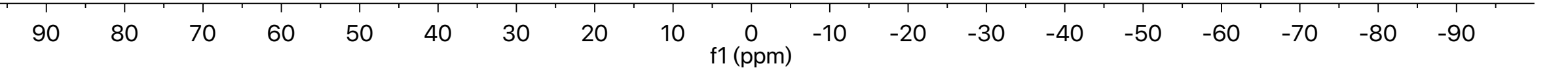




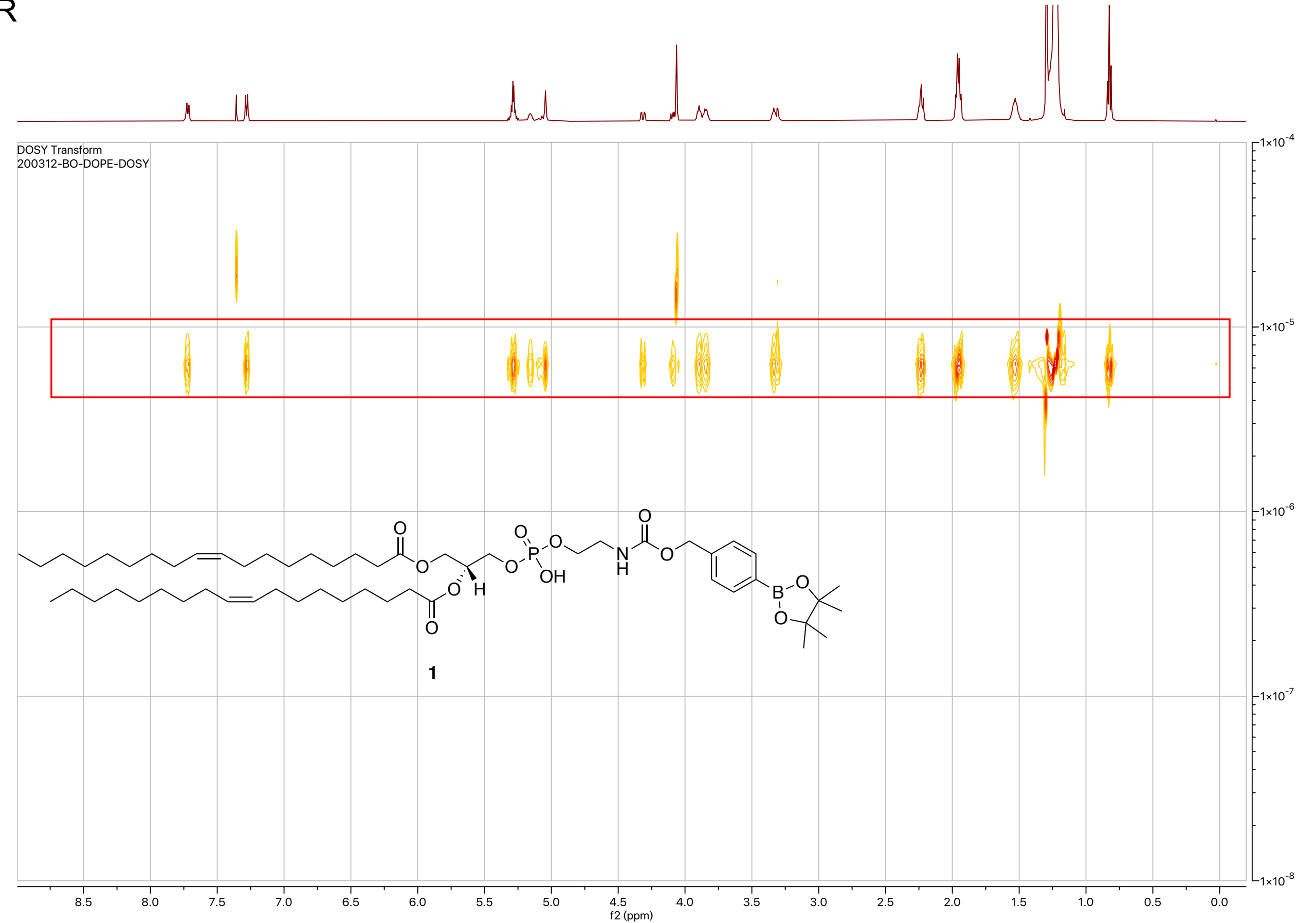




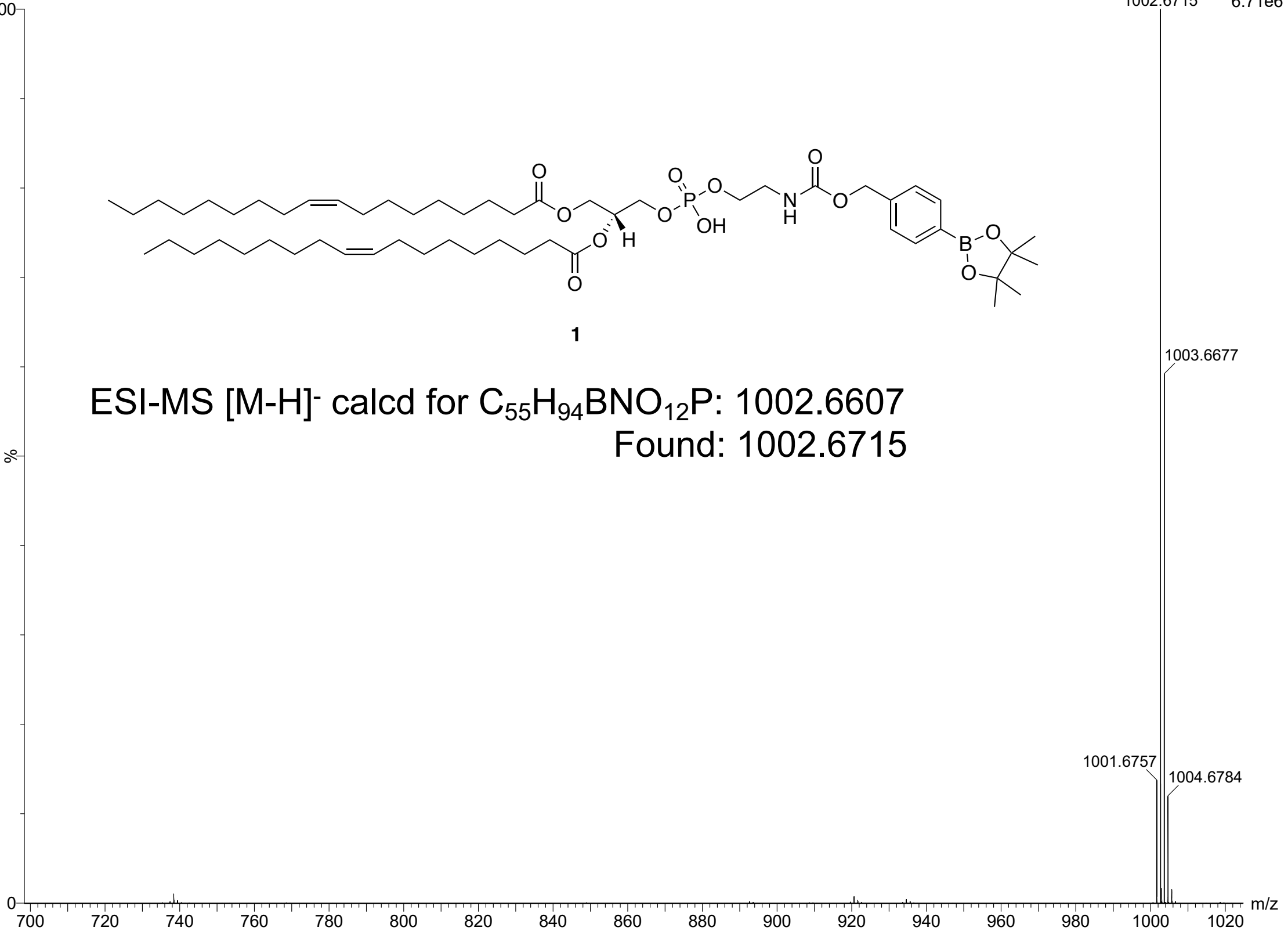




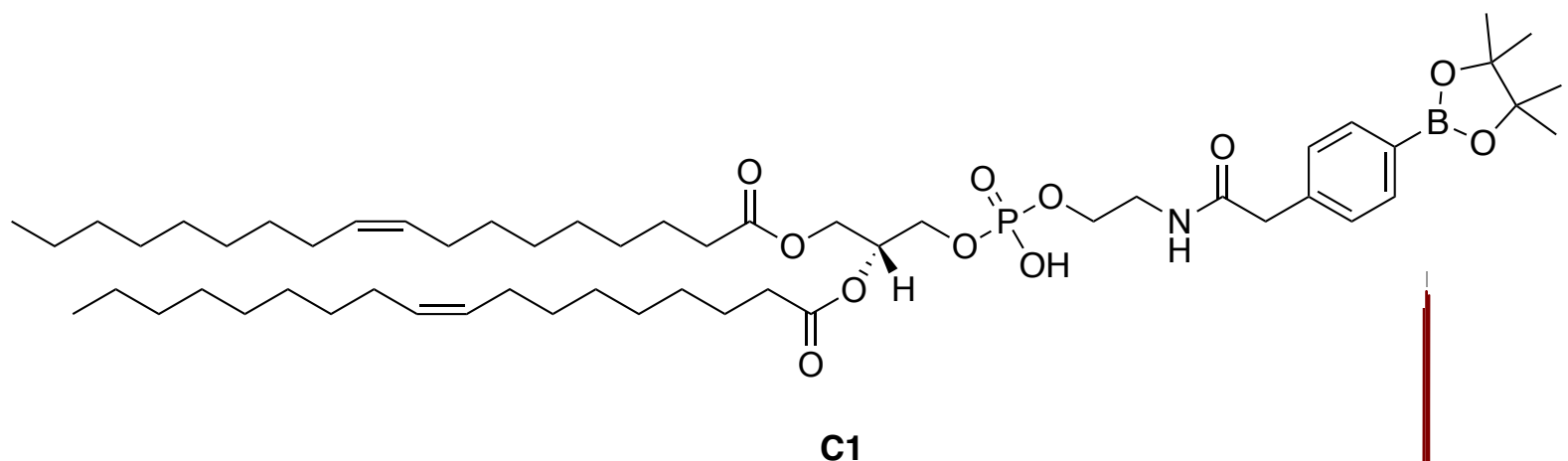

c1

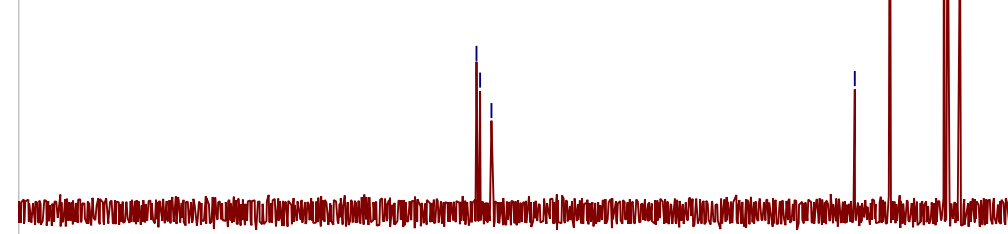




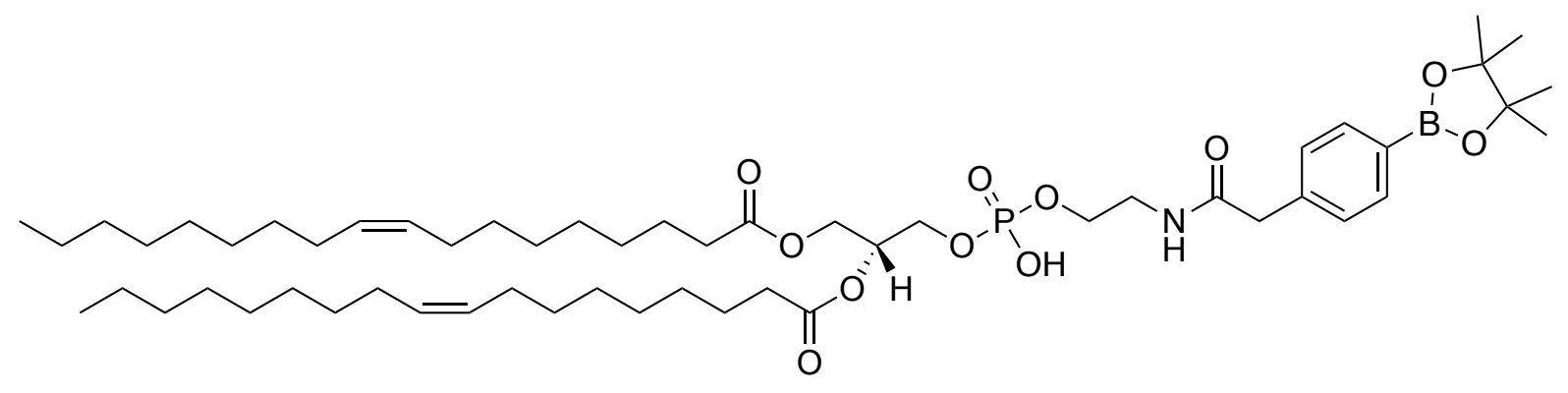




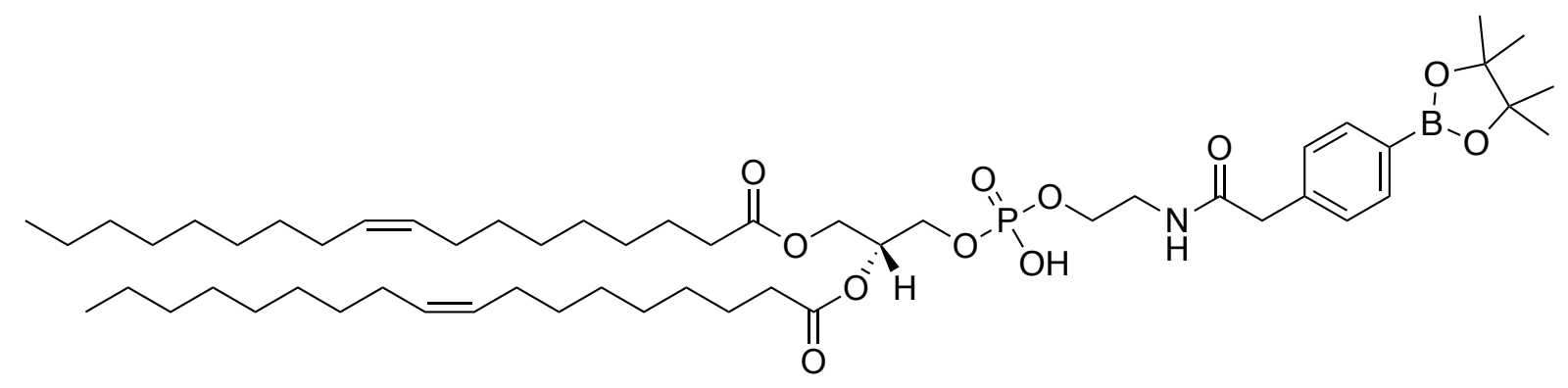

c1

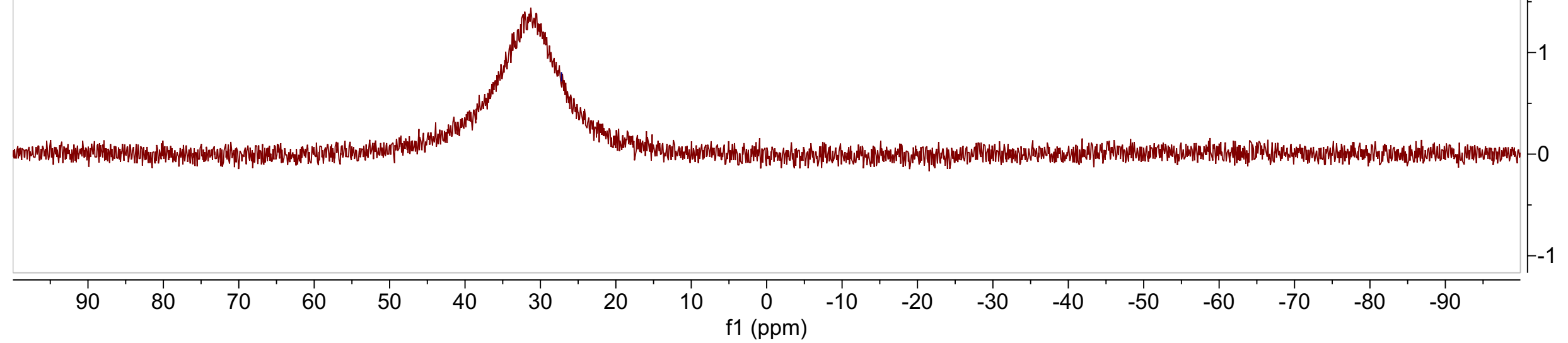




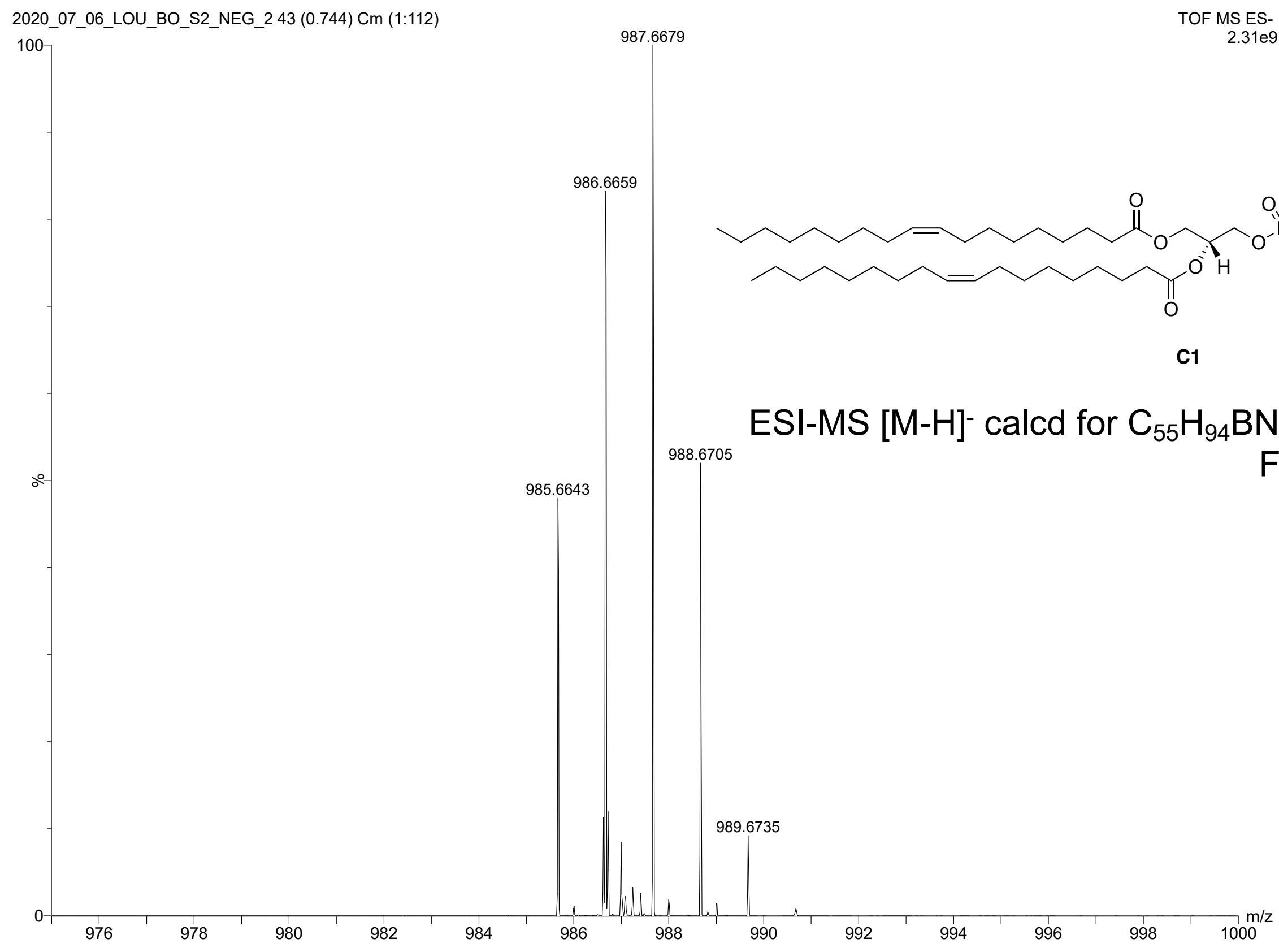

